\title{
ANNOTATIONS
}

\section{Registration of Opticians}

We publish on page 155 of this issue a notice of the Report of the Committee appointed last year to consider the Optical Practitioners' (Registration) Bill (vide Brit. Jl. of Ophthal., Vol. XI, p. 235, 1927). Our readers will be in a position to draw their own conclusions, since we print the recommendations of the majority report in full. It is gratifying to ophthalmologists that the majority report is adverse to the Bill. Neither the majority nor either of the minority reports, however, can be regarded with complete satisfaction. The former, while admitting that there is a prima facie case for setting up a State register in order to produce some sort of order out of the present chaos, considers that a non-prohibitive register would be worse than useless, and that it would not be possible to set up a prohibitive register at the present time. The first of the two minority reports, that signed by three members, takes its stand on the unfortunate prevalence of ignorant and incompetent opticians; they consider that the only way in which to deal with the evil is either to prohibit entirely any unregulated practice, or to provide some means of identification whereby the public may be able to distinguish between regulated and unregulated practice. They conclude that the case for the regulation of the practice of optometry by means of a State register is well supported, and that the Committee incurs a serious responsibility in making an indeterminate report. The last of the three reports emphasizes the fact that the business and practice of optometry is in a state of chaos, and that the number of ophthalmic surgeons is inadequate. It may, however, be pointed out that the number of qualified medical men capable of dealing with errors of refraction has increased rapidly during the last few years, and especially since the institution of the D.O. and D.O.M.S. examinations.

\section{The Bowman Library}

We all know that the library of the Ophthalmological Society, which was presented to the Royal Society of Medicine, has been housed there for many years in an upper room which was seldom visited by any members of either Society. At the same time and in the same building there were the ophthalmological books and periodicals belonging to the Royal Society of Medicine. It was inevitable that in such circumstances there should be overlapping, a state of affairs which has appeared unsatisfactory to each successive librarian of the Bowman Library. About seven years 